\title{
Sperm associations in the male reproductive tract of Eurycea longicauda (Amphibia: Caudata)
}

\author{
A. A. Williams*, J. Martan and R. A. Brandon \\ Department of Zoology, Southern Illinois University at Carbondale, \\ Carbondale, Illinois 62901, U.S.A.
}

Characteristic sperm associations of various patterns and complexities have been reported in the male genital tracts of several mammals (Martan, 1970; Martan, Hruban \& Brown, 1971). Koehring (1925, p. 253), in describing the spermatheca of female Eurycea bislineata, noted spermatozoa in dense whorls and stated (without clarification) that they were "similar to the groups found in the vas deferens of the male." Whorled configurations of spermatozoa have been reported in the spermathecae of Desmognathus fuscus (Marynick, 1971), Notophthalmus viridescens (Benson, 1968) and Gyrinophilus porphyriticus (Dieckmann, 1927) and illustrated, but not discussed, in the vasa deferentia of Ambystoma maculatum (Baker \& Taylor, 1964) and Gyrinophilus porphyriticus (Strickland, 1966). These indications of aggregating spermatozoa in salamanders encouraged us to examine in detail the development of complex sperm associations in the vas deferens of the longtailed salamander, Eurycea longicauda.

The reproductive tracts of 27 adult males collected during April-November 1974 and 1975 were examined. Animals were anaesthetized with tricaine methanesulphonate within $24 \mathrm{hr}$ of capture, and the reproductive tracts (testes, mesorchia with included ducts, and vasa deferentia) were either fixed in situ or excised and fixed for $24 \mathrm{hr}$. Fixatives used were $10 \%$ buffered neutral formalin, Bouin's fluid, Baker's formol with cadmium chloride, or osmium tetroxide. When excised, the reproductive tract was loosely lashed to a microscope slide to maintain anatomical relationships before fixation. Fixation in situ ensured that tissues remained normally apposed and served as a control on anatomical relationships. Fixed tissues were dehydrated in ethanol, cleared in benzene and infiltrated with paraffin wax. Whether excised or fixed in situ, tissues were of the same quality.

The entire reproductive tracts of two specimens (collected in September and October) were serially sectioned at $10 \mu \mathrm{m}$ from the posterior margin of the cloaca to the anterior end of the vas deferens. For the other specimens, only the central third (about $1 \mathrm{~cm})$ of the tract was embedded and serially sectioned at $10 \mu \mathrm{m}$, and every 50th section mounted. Sections were stained with haematoxylin and eosin, Heidenhain's haematoxylin or Mallory's aniline blue technique.

The reproductive tracts of males collected during April-July (14 specimens) did not contain spermatozoa, although the lumen of the vas deferens increased from approximately $10 \mu \mathrm{m}$ in April to $200 \mu \mathrm{m}$ in diameter during July. During August-October (10 specimens) the numbers increased until the lumina of the vasa deferentia were packed with spermatozoa. The vasa deferentia during August were approximately $250 \mu \mathrm{m}$ in diameter and one-third to one-half filled with spermatozoa; during September, they were $300 \mu \mathrm{m}$ in diameter and one-half to three-quarters filled; and during October, they were $300-433 \mu \mathrm{m}$ in diameter and packed with spermatozoa. The vasa deferentia of the November sample ( 2 specimens, postbreeding) were reduced in size (approximately $175 \mu \mathrm{m}$ diameter) and contained few spermatozoa ( $<100 /$ section).

Spermatozoa were seen within the testis, epididymal tubules, vasa deferentia, cloacal tube and cloacal chamber of all 10 specimens examined during the prebreeding period (August-October). Within the lumina of the testicular lobules and the central testicular duct spermatozoa were present singly and in groups (P1. 1, Fig. 2). Each testicular group appeared as a loose association of spermatozoa adhering by their heads and with the tails all trailing behind in a long sweeping arc (PI. 1, Fig. 2). Sections of the epididymal transverse tubules, connecting the central testicular duct to the vasa deferentia, had a luminal diameter of approximately $20 \mu \mathrm{m}$. Some of these contained small numbers

* Present address: Department of Zoology, University of Wisconsin-Milwaukee, Milwaukee, Wisconsin 53201 , U.S.A. 
(maximum 10) of separate spermatozoa (P1.1, Figs 1 and 3), although in most sections from all animals the epididymal tubules appeared empty (Pl. 1, Figs 1 and 3 ).

Within the vas deferens spermatozoa were aggregated into cylindrical associations, morphologically distinct from the groupings seen in the testis. Although the following description is of cylindrical associations within the vasa deferentia, identical associations were present in the cloacal tube and cloacal chamber. These sperm cylinders had an outside diameter of approximately $50 \mu \mathrm{m}$ and a long axis that ranged from 50 to $120 \mu \mathrm{m}$. Each association was formed by a thick $(10-20 \mu \mathrm{m})$ layer of spermatozoa coiled around a clear central area (Pl. 1, Figs 1 and 4). In each cylinder all spermatozoa were orientated in the same direction and mostly in register with one another: head-to-head and tail-to-tail (Pl. 1, Fig. 5).

Cylindrical groups were most prevalent in the central and posterior regions of the vas deferens and most pronounced when only a moderate number of spermatozoa were present. As the number of spermatozoa increased during September, and particularly during October, cylindrical sperm associations became less distinct.

In the vas deferens, the hollow cylindrical bodies appeared randomly arranged; sometimes the long axis was parallel (appearing as a series of circles in cross-sections of the vas) (Pl. 1, Fig. 4) or perpendicular (appearing as a spoked wheel pattern in cross-sections) (Pl. 1, Fig. 1) to the long axis of the vas deferens.

The distinctness of sperm associations in the male reproductive tract of salamanders has probably been overlooked because of their superficial similarity to groups seen in the test is. Sperm groups in the testis are the result of the developmental association of a group of spermatids and their supportive Sertoli cells (Kingsbury, 1902; Pl. 1, Fig. 1). At least some of these groups persist in the testicular lobules and the central duct of the testis after being released from the Sertoli cells (Pl. 1, Figs 2 and 3). To reach the vas deferens spermatozoa must pass through one of a series of epididymal ducts. Since sperm groups were not seen in epididymal tubules, presumably too narrow (approx. $20 \mu \mathrm{m}$ in diam.) to accommodate their passage, spermatozoa in these groups must dissociate before passing individually through the epididymal ducts. Within the vas deferens at least some of the spermatozoa regrouped into new formations, which had a much tighter coil than those found in the testes, forming circles approximately $50 \mu \mathrm{m}$ in diameter (P1. 1, Figs 1 and 4). Since E. longicauda spermatozoa are approximately $475 \mu \mathrm{m}$ long (Wortham, 1975), each spermatozoon could make at most three revolutions per cylinder.

As the vas deferens filled with spermatozoa these cylindrical associations were packed tighter, forming a more regular pattern (Pl. 1, Fig. 1). Cylindrical arrangements were obscured in animals killed during September and October as large numbers of spermatozoa accumulated in the vas deferens during this prebreeding period. However, some cylindrical associations formed in the vas deferens persisted to reach the cloacal tube, and cloacal chamber. Cylindrical associations have been observed in the female spermatheca of a few salamanders (Benson, 1968; Deickmann, 1927; Marynick, 1971) but have not so far been reported in the spermatophore of any salamander. The function of these sperm associations in the male has not been determined. However, similar sperm associations in the female's spermatheca have been postulated to have a nutritive function (Marynick, 1971).

This work was aided by facilities at the School of Medicine, Southern Illinois University at Carbondale. We thank Dr Benjamin Shepherd, Dr Anthony Paparo and Dr John Minnich for their helpful discussions and review of the manuscript, and Dr J. W. Edward Wortham, George Labanick and Gary Nunn for aid in collecting specimens.

\section{References}

BAKER, C.L. \& TAYLOR, W.W., JR (1964) The urogenital system of the male Ambystoma. J. Tenn. Acad. Sci. 19. 1-9.
Benson, D.G. (1968) Reproduction in Urodeles. II. Observations on the spermatheca. Experientia 24, 853-854. 

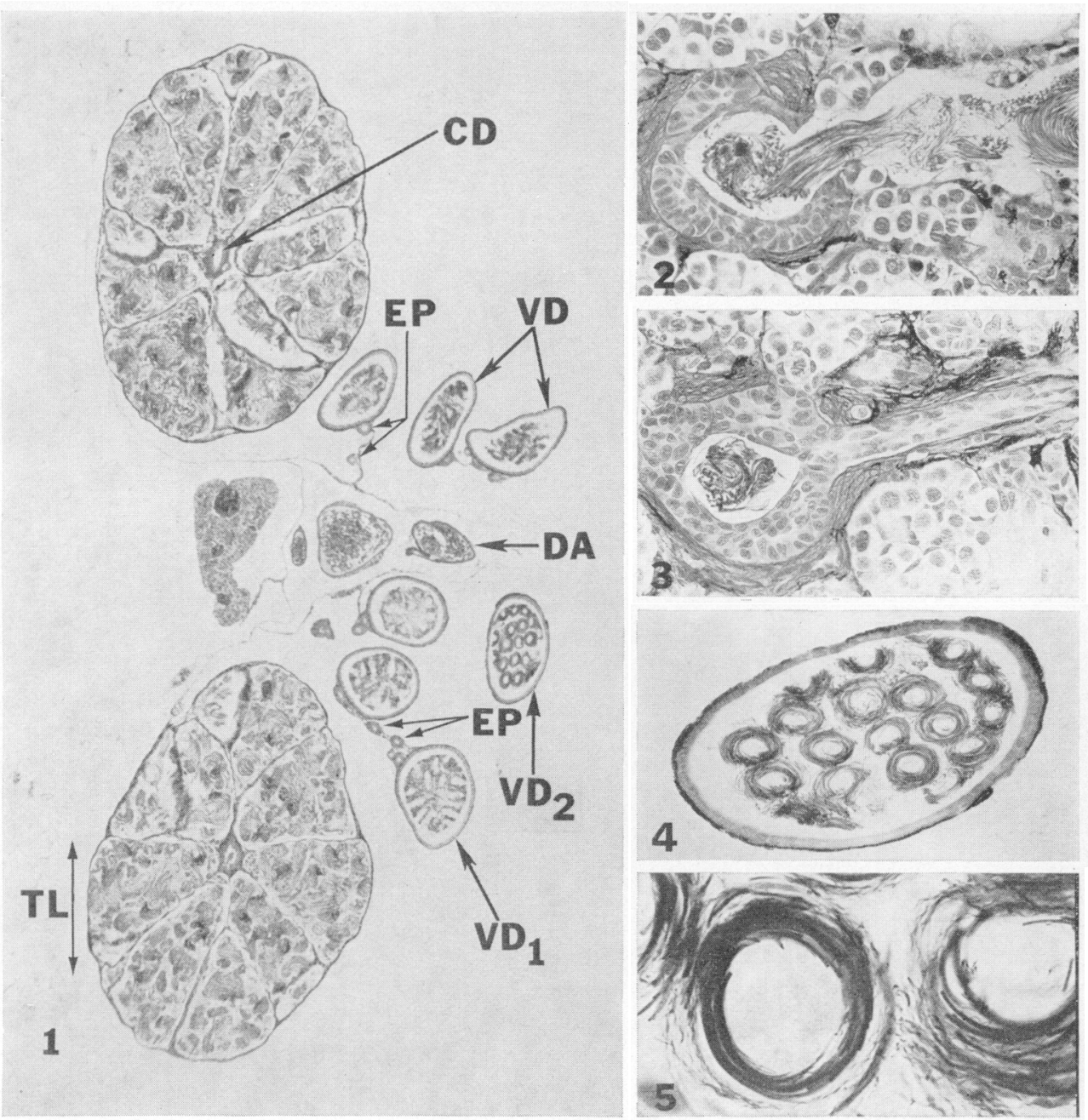

All figures are cross-sections, stained by Mallory's aniline blue technique.

Fig. 1. Reproductive tract of Eurycea longicauda. DA, dorsal aorta; CD, central testicular duct, empty on

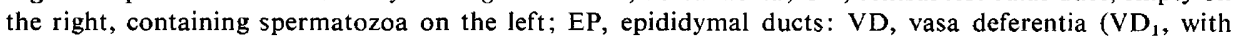
cylindrical sperm associations cut in Iongitudinal section; $\mathrm{VD}_{2}$, with sperm associations in cross-section); TL, testicular lobule, containing groups of spermatozoa embedded in Sertoli cells. $\times 36$.

Fig. 2. Testicular lobule, containing free sperm groups, emptying into the central testicular duct. $\times 110$.

Fig. 3. Central testicular duct, containing sperm groups, opening into the empty epididymal duct. $\times 110$.

Fig. 4. Enlarged view of the vas deferens $\left(\mathrm{VD}_{2}\right)$ in Fig. 1 , showing cylindrical sperm associations cut in cross-section. $\times 100$.

Fig. 5. Sperm associations showing the head-to-head and tail-to tail nature of the association. $\times 500$. 
DieckmanN, J.M. (1927) The cloaca and spermatheca of Hemidactylium scutatum. Biol. Bull. mar. Biol. Lab., Woods Hole 53, 281-285.

Knngsbury, B.F. (1902) The spermatogenesis of Desmognathus fusca. Am. J. Anat. 1, 99-135.

Kozhring, V. (1925) The spermatheca of Eurycea bislineata. Biol. Bull. mar. Biol. Lab., Woods Hole 49, 250-264.

MARTAN, J. (1970) Cohesive properties of mammalian epididymal spermatozoa. $J$. Morph. 132, 389-396.

Martan, J., Hruban, A. \& Brown, P. (1971) The formation and development of the cylindrical bodies in the mammalian epididymis. J. Reprod. Fert. 27, 115-117.

MARYNICK, S.P. (1971) Long term storage of sperm in Desmognathus fuscus from Louisiana. Copeia 1971, 345-347.

Strickland, P. (1966) The urogenital system of Gyrinophilus denielsi dunni. J. Tenn. Acad. Sci. 41, 26-31.

WORTHAM, J.W.E. (1975) Comparative morphology of some plethodontid salamander spermatozoa. Ph.D. Dissertation, Southern Illinois University at Carbondale, Carbondale, Illinois, U.S.A.

Received 4 May 1976 